\title{
Method and description of dynamic vibration reduction in cabins of gantry cranes
}

\author{
Kirill O. Kobzev1,, , Sergey A. Shamshura ${ }^{1}$, Alexander $N$. Chukarin ${ }^{2}$, Vitaliy $P$. \\ Bogdanovich $^{3}$, and Valeriy E. Kasyanov ${ }^{1}$ \\ ${ }^{1}$ Don State Technical University, 344000 Rostov-on-Don, Russia \\ ${ }^{2}$ Rostov State Transport University, 344038 Rostov-on-Don, Russia \\ ${ }^{3}$ State Scientific Establishment "Agriculture research center "Donskoy", North Caucasus Institute of \\ Mechanization and Electrification of Agriculture, 347740 Zernograd, Russia
}

\begin{abstract}
Reduction of vibration in the cabin can be achieved by increasing the area of vibration absorption by placing on the ceiling and floor vibro-absorbing facings. The process of absorption of vibration occurs due to the transition of the energy of oscillating particles to heat due to frictional losses in the pores of the material; therefore, for effective vibration absorption, the material must have a porous structure, the pores must be open from the side of the vibration and join together (unclosed pores) so as not to prevent the penetration of the vibration wave into the thickness of the material. As a vibration-absorbing cladding, we use a construction in the form of a layer of a homogeneous porous material of a certain thickness, reinforced directly on the surface of the fence.
\end{abstract}

Throughout the world, when working in warehouses, performing construction, installation, transportation and loading operations, gantry cranes are used. In the gantry cranes, the maximum value is given to the lifting capacity, lifting height, service area, high productivity, the ability to position cargoes as precisely as possible, to high reliability indicators, and the truck's own stability and crane stability are also given the utmost attention. Preservation of health and efficiency of operators of gantry cranes from the influence of hazardous and harmful factors is one of the fundamental problems in the field of labor protection on cranes of various purposes in industry. On a number in comparison of cranes of various purposes, gantry cranes are the subject of increased danger. When gantry cranes work, not only service personnel are exposed to danger, but also persons in the working area of the lifting device. There are three main causes of accidents on gantry cranes - the destruction of ropes, the destruction of structural elements and fatigue of operators. The main harmful factor, the longterm effect of which affects the operator's fatigue and consequently leads to a decrease in labor productivity and occupational diseases, is vibration. The carried out analysis of scientific works has shown that the question of the influence of vibration characteristics in cabins of gantry cranes at workplaces on the safety of operators has not been sufficiently studied. In connection with the foregoing, the task of lowering the level of vibration to sanitary standards in cabins of gantry cranes at crane workplaces is urgent and will affect scientific, technical, social and economic significance.

* Corresponding author: kobzevkirill1990@mail.ru 
At present, sound-absorbing materials such as ultra-thin glass fibers, mineral wool, fibreboard and mineral boards, porous polyvinyl chloride and other materials are used. The installation of vibration-absorbing liners reduces vibration by 6-8 dB. Despite such a relatively small reduction in vibration, the use of veneers is advisable, since the vibration spectrum in the cabin varies due to the high efficiency of the lining. Vibro-absorbing materials are some varieties of rubber and mastic, foil-isoel, sheet plastics. Vibrationabsorbing materials are applied to thin metal surfaces, while creating an efficient vibrationabsorbing construction with high energy for friction. There is a rather large selection of materials for vibration isolation, both universal and special purpose. We also reviewed materials specifically designed for vibration isolation in engineering. These materials differ not only in the composition of the substrate, but also in the application conditions, the operating temperature range and the health hazard. Often, you can find examples when using for vibration isolation roofing or building materials based on bitumen (gerlen), tk. are economically viable. But the effectiveness of such materials is much lower, and the inhalation of vapors of such materials can be very harmful, because they are designed for outdoor use. The types and main characteristics of the materials for the vibration isolation of the cockpit are considered, which are used most often. Materials of GC "Standardplast" were considered. The manufacturer indicates that virtually all materials for vibration isolation range of temperatures in which the material does not lose its properties, is wide enough (from $-45^{\circ} \mathrm{C}$ to $100^{\circ} \mathrm{C}$ ). Any vibration isolation changes its properties when temperature changes. For vibro-facing is the most suitable combination such as "asbosiliterubber". It should be noted that the vibration levels in the cab fixation points exceed the ceiling levels by no more than $1.5 \mathrm{~dB}$, which practically corresponds to the accuracy of the measuring equipment. Since excess vibration conditions were fixed in octaves with average geometric frequencies of 8.16 and $31.5 \mathrm{~Hz}$, data on vibration levels in the octave with a mean geometric frequency of 63 were not indicated. The results of the measurements showed that the maximum values of the excess levels of vibration were fixed in an octave with a mean geometric frequency of $8 \mathrm{~Hz}$, and reached $12 \mathrm{~dB}$. In an octave with a mean geometric frequency of $16 \mathrm{~Hz}$, the maximum excess is $3 \mathrm{~dB}$ lower and is $9 \mathrm{~dB}$. In an octave with a mean geometric frequency of $31.5 \mathrm{~Hz}$, only for cranes with a carrying capacity of 100 tons or more, vibration levels exceed 1-2 dB. It should be noted that the levels of vibration on the ceiling, i.e. in places of fixing the cab is 7-9 dB higher than on the floor. Therefore, in order to reduce vibration levels at the workplace of the crane operator, the most technically justified method is to increase the dissipative characteristics of the ceiling and the floor of the cabin and to achieve a smooth movement of the mobile crane bodies by replacing the safety clutch.

To reduce the vibration indices on the floor, laminates were used directly at the crane operator's workplace, such as: incombustible constructional finishing boards "Asbosilit 609", wood-fiber plates "Ramolit-1", magnetoplast and all three materials in combination with rubber brand 102 .

The optimal theoretical value of vibration damping indices when using the layered structure indicated above was calculated by the formula:

$$
\Delta L_{v}=10 \lg \frac{\eta_{\Sigma}}{\eta_{0}}
$$

$\eta_{\mathbf{b}}$ - coefficient of loss of vibrational energy of the cabin base (steel);

$$
\eta_{\Sigma}=\frac{\sum \frac{E_{i} h_{i}^{3}}{12\left(1-M_{i}^{2}\right)} \eta_{i}}{\sum \frac{E_{i} h_{i}^{3}}{12\left(1-M_{i}^{2}\right)}} .
$$


As a result of the theoretical calculation, the optimal combination of materials to reduce vibration by $8 \mathrm{~dB}$ is (wood-fiber plates "Ramolit-1" $10 \mathrm{~mm}$ thick and rubber grade 102 $10 \mathrm{~mm}$ ), to reduce vibration by $12 \mathrm{~dB}$ - (plates incombustible structural finishing "Asbosilite $609 "-5 \mathrm{~mm}$, and the rubber grade $102-10 \mathrm{~mm}$ ).

Moreover, it should be noted that to create safe working conditions for crane operators on cranes with a load capacity of up to 50 tons, to reduce the level of vibration to the remote control, it is sufficient to use only a layered floor structure. For cranes with a load capacity of more than 50 tons, to reduce the vibration index by $12 \mathrm{~dB}$ is not fulfilled. Reduction in vibration levels is $10 \mathrm{~dB}$, i.e. the standard is exceeded by $2 \mathrm{~dB}$. In this case, it is advisable to use a coupling with improved flywheel moments and a pusher ratio. The installation of the developed coupling in the drive for moving the trolley of the gantry crane resulted in a decrease in vibration levels on the rail by 4-6 dB and on the floor of the cabin by 2-2.5 $\mathrm{dB}$. In this case, the vibration levels at the crane operator's workplace are brought to sanitary standards.

\section{References}

1. Ji. A. Borisov, G. D. Yanovsky, Acoustic suspended ceilings with sound-absorbing mineral wool products (Tr. Central Research Institute of Industrial Facilities, Moscow, 1981)

2. I. I. Bogolepov, B. M. Efimtsev, V. F. Panin, Tr. TsAGI, 1920, 39 (1978)

3. E. I. Avferonok, N. G. Belyakovskiy, I. I. Bogolepov et al, Reference book on ship acoustics (Shipbuilding, Leningrad, 1978)

4. S. P. Timoshenko, S. Voinovsky-Krieger, Plates and shells (Science, Moscow, 1966)

5. A. C. Nikiforov, Acoustic design of ship structures: Reference book (Shipbuilding, Leningrad, 1990)

6. N. I. Ivanov, Combating noise and vibrations on track and construction machines (Transport, Moscow, 1987)

7. L. G. Ba-lishanskaya, L. F. Drozdova, N. I. Ivanov et al. Ed. N.I. Ivanova, Technical acoustics of transport vehicles: Reference book (Polytechnica, Saint Petersburg, 1992)

8. N. I. Ivanov, A. C. Nikiforov, Fundamentals of vibroacoustics (Polytechnica, Saint Petersburg, 2000)

9. L. P. Borisov, D. R. Guzhas, Soundproofing in mechanical engineering (Mechanical engineering, Moscow, 1990)

10. N. I. Ivanov, Engineering acoustics. Theory and practice of noise control: a textbook (University book, Logos, Moscow, 2008)

11. V. A. Gergert, Reduction of noise at the workplaces of road train drivers by providing the required soundproofing properties and dissipative parameters of the cabin: (Author's abstract. dis. Cand. tech. sciences, 2002)

12. V. Z. Vlasov, Selected works in 3 volumes, III (Publishing House of the USSR Academy of Sciences, Moscow, 1963)

13. A. N. Chukarin, Theory and methods of acoustic calculations and design of technological machines for machining: monograph (Publishing Center of the State Technical University, Rostov n / a, 2004) 